\title{
Complex investigations of structural and thermal properties of silica-titania adsorbents
}

\author{
J. Skubiszewska-Zięba $\cdot$ B. Charmas • \\ R. Leboda $\cdot$ V. A. Tertykh $\cdot$ V. V. Yanishpolskii
}

ICVMTT2011 Conference Special Chapter

(C) The Author(s) 2011. This article is published with open access at Springerlink.com

\begin{abstract}
Mesoporous titanium-containing silicas with different Titania contents were investigated. The structural parameters of the materials were characterized by lowtemperature adsorption/desorption of nitrogen and X-ray diffraction analysis. The thermodesorption of water using the quasi-isothermal thermogravimetry as well as the differential scanning calorimetry were used to characterize thermal and surface properties of these materials. The adsorbed water layers and the concentration of weakly and strongly bound water as well as the surface free energy on the adsorbent/water interfaces were calculated. It was stated that the increase of Titania content causes a gradual decrease of specific surface area and formation of biporous structure inside the tested materials. The water thermodesorption from the surface proceeds in two or three stages, which is connected mainly with pore distribution and $\mathrm{TiO}_{2}$ content. One can observe the increase of the total surface free energy $\left(\Delta G_{\Sigma}\right)$ with the increasing $\mathrm{TiO}_{2}$ content, but the largest $\Delta G_{\Sigma}$ value at the adsorbent/strongly bound water interface is exhibited by the adsorbent of intermediate content $(30 \%)$ of $\mathrm{TiO}_{2}$. Freezing temperature of water contained in the pores of the studied materials is connected largely with their porous structure. Due to the well developed porous structure, the water freezing process is a multistage one.
\end{abstract}

J. Skubiszewska-Zięba $\cdot$ B. Charmas $(\bowtie) \cdot$ R. Leboda Department of Chromatographic Methods, Faculty of Chemistry, Maria Curie-Sklodowska University, Maria Curie-Sklodowska Sq.3, 20-031 Lublin, Poland e-mail: barbara.charmas@ poczta.umcs.lublin.pl

V. A. Tertykh · V. V. Yanishpolskii Institute of Surface Chemistry, National Academy of Science of Ukraine, Kiev 252022, Ukraine
Keywords Mesoporous titanosilicas · Porous structure · Q-TG · DSC · Water layers · Surface free energy

\section{Introduction}

The rapid development of research on the preparation of ordered mesoporous materials began in the early 1990s [1], when the Mobil Corporation has reported new method of materials designated as M41S synthesis. Such materials are characterized by high specific surface area and well developed porous structure with ordered framework and narrow pore size distribution. The structure of mesoporous materials allows using them as host materials, catalyst for reactions of large molecules [2] and chromatographic materials. They can be modified by incorporation of different metals in the form of elements, ions or oxides which can create or enlarge the activity inside the pores. The incorporation of ions of transition metals into the framework of such materials (especially titanium) gives additional special catalytic properties [3-11].

Silica-titania materials (STM) possessing different compositions and physico-chemical characteristics are widely used as fillers, pigments, catalysts, catalyst supports, etc. [3, 12-14] They also demonstrate photocatalytic and oxidative activity $[15,16]$. Mesoporous titania-silica materials can be prepared by three methods [17]: (1) onepot synthesis (the metal precursor is added directly to a silicon source and metal becomes part of the wall structure) $[6,18],(2)$ template ion-exchange (the ion template in asprepared material is exchanged with other metal ions from the solution) [19] as well as (3) post-synthesis modification (numerous $\mathrm{Si}-\mathrm{OH}$ groups react with the organometallic complex or another source of metal) [20, 21]. It is known that the synthesis techniques used for preparation (sol-gel, 
Table 1 Structural parameters of silica-titania adsorbents

\begin{tabular}{llllll}
\hline Sample & $\begin{array}{l}\mathrm{TiO}_{2} \text { content/ } \\
\mathrm{mol} \%\end{array}$ & $\begin{array}{l}S_{\mathrm{BET}} / \\
\mathrm{m}^{2} / \mathrm{g}\end{array}$ & $\begin{array}{l}V_{\mathrm{p}} / \\
\mathrm{cm}^{3} / \mathrm{g}\end{array}$ & $\begin{array}{l}R_{\text {ave }} / \\
\mathrm{nm}\end{array}$ & $R_{\mathrm{dom}} / \mathrm{nm}$ \\
\hline $\mathrm{ST}_{1}$ & 1 & 924 & 0.47 & 1.0 & 1.04 \\
$\mathrm{ST}_{15}$ & 15 & 805 & 0.45 & 1.1 & $1.04 ; 2.13$ \\
$\mathrm{ST}_{30}$ & 30 & 702 & 0.52 & 1.5 & $1.14 ; 2.02$ \\
$\mathrm{ST}_{50}$ & 50 & 529 & 0.59 & 2.3 & 1.89 \\
$\mathrm{ST}_{70}$ & 70 & 353 & 0.45 & 2.6 & 2.43 \\
\hline
\end{tabular}

high-temperature hydrolysis, chemical vapor deposition CVD) strongly affect the structure and properties of STM. Titania-silicas can possess (a) complex structure both in the bulk and at the surface layer, as it is in the fumed ST or (b) separated phases of $\mathrm{TiO}_{2}$ and $\mathrm{SiO}_{2}$ with a clear-cut phase boundary when one of these oxides is formed on another, which is a substrate (e.g., using the CVD technique). Naturally, the activity of solids in various adsorption and catalytic processes is affected by many factors, i.e., porous structure, chemical nature of surface functional groups and their natural distribution and concentration [2224]. The surface and sorption properties of such materials depend strongly on the degree of hydration, i.e., the amount of bound and physically adsorbed water. Many studies suggest that the water contained in pores of such materials changes its physicochemical properties because of interactions with the solid surface [25-27]. Thus, studying the phase transitions of water bound to the surface of such materials we obtain additional information about their porous structure and the nature of the surface.

The aim of this article was to investigate the effect of chemical compositions $\left(\mathrm{SiO}_{2} / \mathrm{TiO}_{2}\right)$ and the porosity of a series of silica-titania adsorbents on the structure of adsorbed water layers.

\section{Experimental}

Titania-silica samples (containing from 1 to $70 \mathrm{~mol} \%$ of $\mathrm{TiO}_{2}$ ) were prepared by using the templating approach to synthesize mesoporous silica-based molecular sieves partly substituted with titanium-large-pore analogs of titanium silicalite. The reaction of TEOS and $\mathrm{Ti}\left(\mathrm{i}-\mathrm{OC}_{3} \mathrm{H}_{7}\right)_{4}$, as $\mathrm{SiO}_{2}$ and $\mathrm{TiO}_{2}$ precursors, with octadecyltrimethylammonium chloride (ODTMA) as a template was performed. The ratio of ODTMA: $\left(\mathrm{SiO}_{2}+\mathrm{TiO}_{2}\right)$ was equal to 0.27 . The details of the preparation procedure were described in [14].

The characterization of synthesized samples was performed by nitrogen adsorption/desorption isotherms measured at $77 \mathrm{~K}$ using the ASAP 2405 Micromeritics apparatus. The specific surface area $\left(S_{\mathrm{BET}}\right.$, Table 1$)$ was calculated using the BET equation [28] at $p / p_{\mathrm{o}}$ between 0.06 and 0.2 (where $p$ and $p_{\mathrm{o}}$ denote the equilibrium and saturation pressure of nitrogen, respectively). The pore volume $V_{\mathrm{p}}$ was determined at $p / p_{\mathrm{o}} \approx 1$. The average pore radius $\left(R_{\text {ave }}\right)$ was calculated using a cylindrical pore model $R_{\mathrm{p}}=2 V_{\mathrm{p}} / S_{\mathrm{BET}}$. Pore volume distributions in the function of their radius were calculated according to the BarrettJoyner-Halenda (BJH) method [29]. On the basis of this dependence the dominant pore radius $\left(R_{\mathrm{dom}}\right)$ was determined. The X-ray diffraction analysis (XRD) was performed using the automated diffractometer DRON-3M, $\mathrm{Cu}-\mathrm{K}_{\alpha}$ radiation.

Thermodesorption of water from the surface of investigated samples was carried out under quasi-isothermal conditions (Q-TG) in the range of 293-573 K using a Derivatograph C (Paulik, Paulik and Erdey, MOM, Hungary). Before the Q-TG measurements the water vapor was adsorbed on the surface of studied samples at room temperature $(293 \mathrm{~K})$ for $72 \mathrm{~h}$. Then the weighed portions (about $50 \mathrm{mg}$ ) of adsorbents were placed in the special
Fig. 1 Low-temperature adsorption/desorption of nitrogen (a) and pore volume distribution functions in respect to their radius (b) for the silicatitania adsorbents
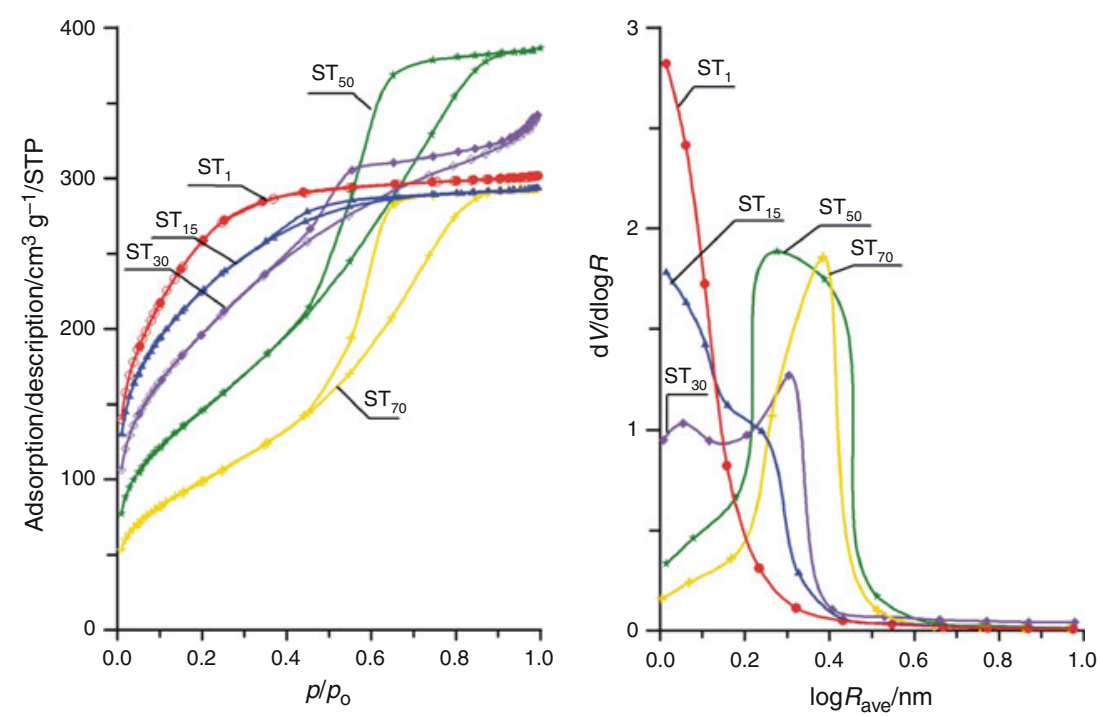



Fig. 2 The Q-TG and Q-DTG curves of water thermodesorption from the tested adsorbents

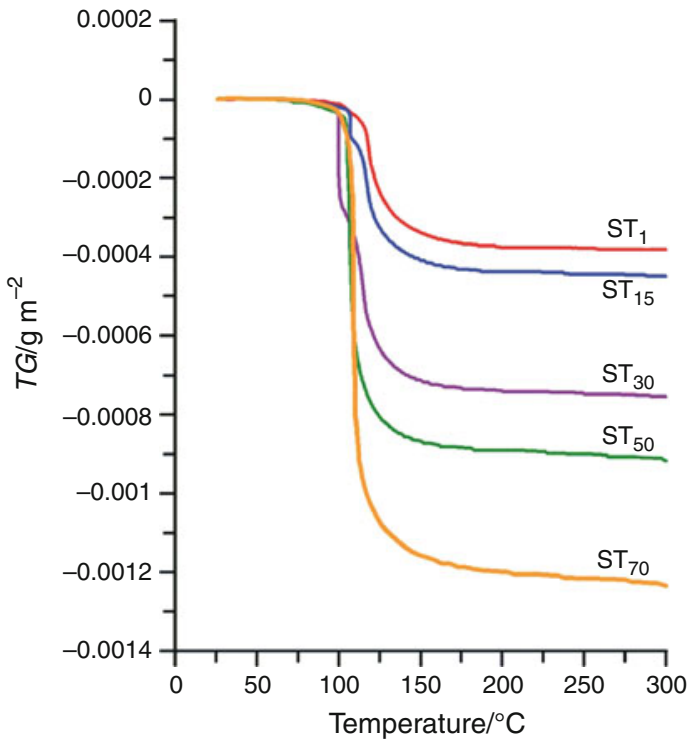

Fig. 3 The course of water mass loss curve as a function of the temperature increase

spherical platinum crucible of the derivatograph. The experimental data of quasi-thermogravimetric measurements correspond to water mass loss in accordance with temperature changes. When measurements are performed over a temperature range without any chemical reactions leading to changes in the sample mass then the $\Delta m=f(T)$ dependence reflects changes in concentration of the substance present on the adsorbent surface under equilibrium. These data were used as initial ones for calculation of energetic characteristics of the tested samples. This method was described precisely in $[30,31]$. On the basis of the obtained data, total concentrations of water adsorbed on the surface of studied adsorbents $(\mathrm{mg} / \mathrm{g})$ were calculated. The number of statistical monolayers " $n$ " of water was determined from the formula:

$n=\frac{T G_{\max } N_{\omega}}{S_{\mathrm{BET}} M}$

where $\omega$-the surface occupied by one adsorbed water molecule (assumed $0.09 \mathrm{~nm}^{2}, N$-the Avogadro number, $S_{\mathrm{BET}}$ - the specific surface area of the tested adsorbents $\left(\mathrm{m}^{2} / \mathrm{g}\right), T G_{\max }$ - the maximum mass loss at $573 \mathrm{~K}(\mathrm{mg} / \mathrm{g})$, $M$-molar mass of water $(18 \mathrm{~g} / \mathrm{mol})$.

Thermal properties of the silica-titania adsorbents were performed using Differential Scanning Calorimetry (DSC PYRIS Diamond Perkin Elmer, USA). The DSC method was used to indicate the energetic effects of the interfacial phenomena, which takes place during freezing of strongly and weakly bound water connected with the surface of tested adsorbents.

\section{Results and discussion}

Low-temperature adsorption/desorption of nitrogen and pore volume distribution functions in respect to their radius for the silica-titania adsorbents are presented in Fig. 1. As follows from the course of the curves of adsorptiondesorption isotherms (Fig. 1a), the smaller is the $\mathrm{TiO}_{2}$ content in the sample mass, the larger is contribution of micropores. The $\mathrm{ST}_{1}$ adsorbent is microporous, the adsorption isotherm reaches plateau at higher values of pressure and does not exhibit a hysteresis loop. With the $\mathrm{TiO}_{2}$ increase in the sample mass, drop in the micropore volume is observed. For the adsorbents $\mathrm{ST}_{15}$ and $\mathrm{ST}_{30}$ the structure becomes bimodal, i.e., we can observe two peaks corresponding to 
Fig. 4 The dependence of water free energy changes on the function of its concentration on the surface of the studied silica-titania adsorbents
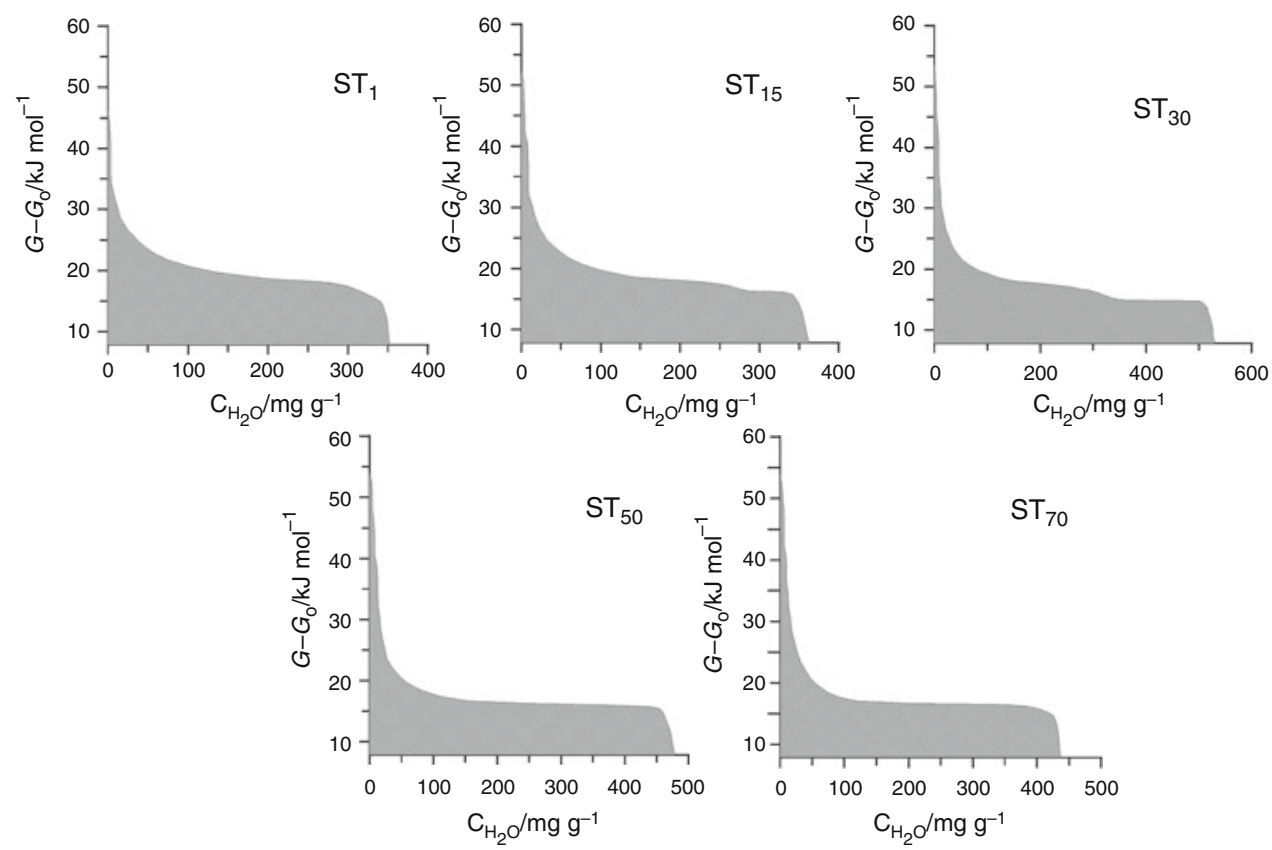

Table 2 Characterization of water adsorbed on the silica-titania adsorbents surface

\begin{tabular}{|c|c|c|c|c|c|c|c|}
\hline Sample & $S_{\mathrm{BET}} / \mathrm{m}^{2} / \mathrm{g}$ & $\mathrm{C}_{\mathrm{H}_{2} \mathrm{O}}^{\max } \mathrm{mg} / \mathrm{g}$ & $n$ & $\Delta G^{\mathrm{s}} / \mathrm{kJ} / \mathrm{mol}$ & $\Delta G^{\mathrm{b}} / \mathrm{kJ} / \mathrm{mol}$ & $\Delta G_{\Sigma}^{\mathrm{s}} / \mathrm{kJ} / \mathrm{m}^{2}$ & $\Delta G_{\Sigma} / \mathrm{kJ} / \mathrm{m}^{2}$ \\
\hline $\mathrm{ST}_{1}$ & 924 & 352.4 & 1.15 & 35.4 & 18.6 & 47 & 261 \\
\hline $\mathrm{ST}_{15}$ & 805 & 362.6 & 1.36 & 37.7 & 16.5 & 86 & 291 \\
\hline $\mathrm{ST}_{30}$ & 702 & 529.8 & 2.27 & 39.0 & 15.0 & 145 & 438 \\
\hline $\mathrm{ST}_{50}$ & 529 & 478.3 & 2.76 & 37.7 & 16.3 & 92 & 506 \\
\hline $\mathrm{ST}_{70}$ & 353 & 436.2 & 3.72 & 37.3 & 16.7 & 122 & 710 \\
\hline
\end{tabular}

$\mathrm{C}_{\mathrm{H}_{2} \mathrm{O}}^{\max }$ is the maximal concentration of adsorbed water, $n$ - the number of statistical adsorbed water layers, $\Delta G^{\mathrm{s}}$ is a maximal value of changes in free energy for strongly adsorbed water, $\Delta G^{\mathrm{b}}$ is the change in free energy of water during its evaporation from filled pores, $\Delta G_{\Sigma}^{\mathrm{s}}$ is the surface free energy at the adsorbent/strongly bound water interface, $\Delta G_{\Sigma}$ is the total surface free energy at the adsorbent/water interface

narrower pores on the curve of pore volume distribution with respect to their average radius (Fig. 1b). These values are: $R=1.04 \mathrm{~nm}$ and $2.13 \mathrm{~nm}$ for $\mathrm{ST}_{15}$, as well as $R=1.14$ and $2.02 \mathrm{~nm}$ for $\mathrm{ST}_{30}$ samples, respectively. The isotherms of the samples $\mathrm{ST}_{50}$ and $\mathrm{ST}_{70}$ are characterized by much lower adsorption in the range of low relative pressures and distinct hysteresis loops in that of high relative pressure. This gives a reflection in the course of the pore volume distribution functions on which we observe single peaks with the values of dominant radius $R_{\text {dom }}$ equal to 1.89 and $2.43 \mathrm{~nm}$ for $\mathrm{ST}_{50}$ and $\mathrm{ST}_{70}$, respectively. The XRD analysis reveals that $\mathrm{TiO}_{2}$ is in the form of anatase. The structural parameters of these adsorbents are shown in Table 1.

Figure 2 shows the experimental curves of water thermodesorption from the surface of the studied adsorbents as well as the DTG curves indicating the process rate depending on temperature. As can be seen larger the $\mathrm{TiO}_{2}$ content is, the less complex is the thermodesorption of water from the pores. Three stages of this process are observed for the adsorbents $\mathrm{ST}_{1}, \mathrm{ST}_{15}$, and $\mathrm{ST}_{30}$ but only two for $\mathrm{ST}_{50}$ and $\mathrm{ST}_{70}$. Thermodesorption of weakly bound water from the $\mathrm{ST}_{50}$ and $\mathrm{ST}_{70}$ samples proceeds at lower temperatures and the inflection point occurs at $110{ }^{\circ} \mathrm{C}$ (Fig. 2). The other part of the water desorbs monotonically without visible stages pointing to a quick process. However, in the case of $\mathrm{ST}_{1}$ and $\mathrm{ST}_{15}$ the amount of weakly bound water is significantly smaller than that of strongly bound water desorbing at higher temperatures (above $110^{\circ} \mathrm{C}$ ). The intermediate properties with respect to the proportion of weakly and strongly bound water are exhibited by $\mathrm{ST}_{30}$. Figure 2 shows the distinct differences in the course of vertical parts of the curves (desorption at different temperatures) as well as in the horizontal parts corresponding to differentiated sorption capacities of these adsorbents for water molecules. A good illustration is the summary picture presenting the curves of the water thermodesorption course in the temperature function (Fig. 3). 
The shape of water thermodesorption curves correlates well with the courses of pore distribution functions with respect to their effective radius (Fig 1b). As can be seen the adsorbents $\mathrm{ST}_{1}$ and $\mathrm{ST}_{15}$ possessing mainly pores of narrow dimensions retain water molecules more strongly than the adsorbents $\mathrm{ST}_{50}$ and $\mathrm{ST}_{70}$ which exhibit porosity in the area of wider pores. However, the intermediate adsorbent $\mathrm{ST}_{30}$ is characterized by the balanced proportion between narrow pores and wide pores as evidenced by the TG curve course (Fig. 3).

Two boundary phases exist on the adsorbent surface, when water is adsorbed on it, i.e., the adsorbent/water and

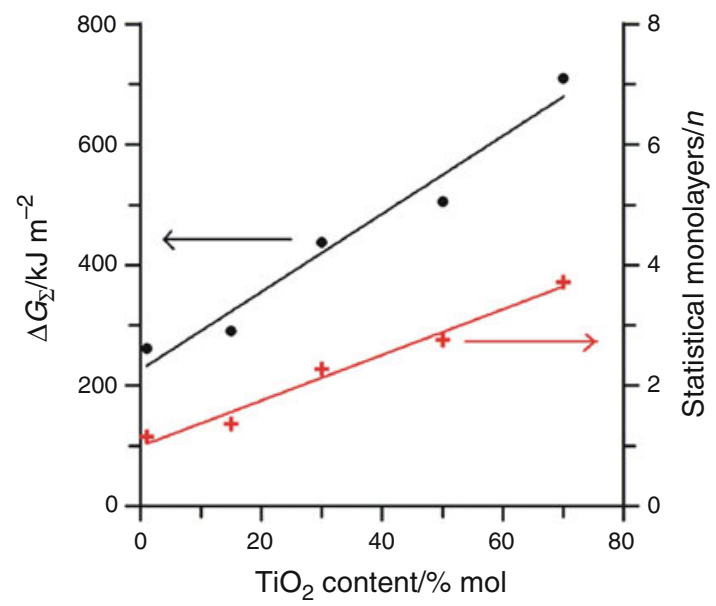

Fig. 5 The surface free energy at the adsorbent/water interface $\left(\Delta G_{\Sigma}\right)$ and the number of statistical water monolayers $(n)$ in the dependences from the $\mathrm{TiO}_{2}$ content

water/air interfaces. Thus, different reasons for a decrease in the Gibbs free energy of water at the adsorbent/water interface can be distinguished. These changes are caused by the strong adsorption of water molecules on the adsorbent surface centers $\left(\Delta G^{\mathrm{s}}\right)$, capillary condensation in the pores $\left(\Delta G^{\mathrm{por}}\right)$, and the presence of water/air interface $\left(\Delta G^{\mathrm{air}}\right)$ [31]. When the Gibbs free energy of adsorbed water is equal to that of water in the gas phase (this process depends on the temperature and this is the condition for evaporation of adsorbed water), water begins to desorb from the surface when its Gibbs free energy becomes equal to that of water vapor at a given temperature (enabling possibility the phase transition). The thermodynamic function of the water vapor can be calculated using the equation:

$\Delta G=G-G_{\mathrm{o}}=0.197\left(T-T_{\mathrm{o}}\right)$

where $T_{\mathrm{o}}$ is the standard temperature $293 \mathrm{~K}$. On the basis of $\Delta m_{\mathrm{H}_{2} \mathrm{O}}=f(T)$ experimental data (Q-TG) the dependences of changes in the Gibbs free energy on the concentration of the adsorbed water were determined, $\Delta G=f\left(\mathrm{C}_{\mathrm{H}_{2} \mathrm{O}}\right)$.

Figure 4 presents the dependences of change of water free energy in the function of its concentration on the surface of the studied silica-titania adsorbents. The marked areas under these dependences were used to calculate the values of total surface free energy at the adsorbent/water interface $\left(\Delta G_{\Sigma}\right)$. However, the parts of these areas (corresponding to low concentrations of adsorbed water) were used to calculate the surface free energy at the adsorbent/ strongly bound water interface $\left(\Delta G_{\Sigma}^{\mathrm{s}}\right)$. The corresponding

Fig. 6 The $\mathrm{d} G / \mathrm{d} M$ dependences as a function of statistical monolayers of water clusters for the silica-titania adsorbents
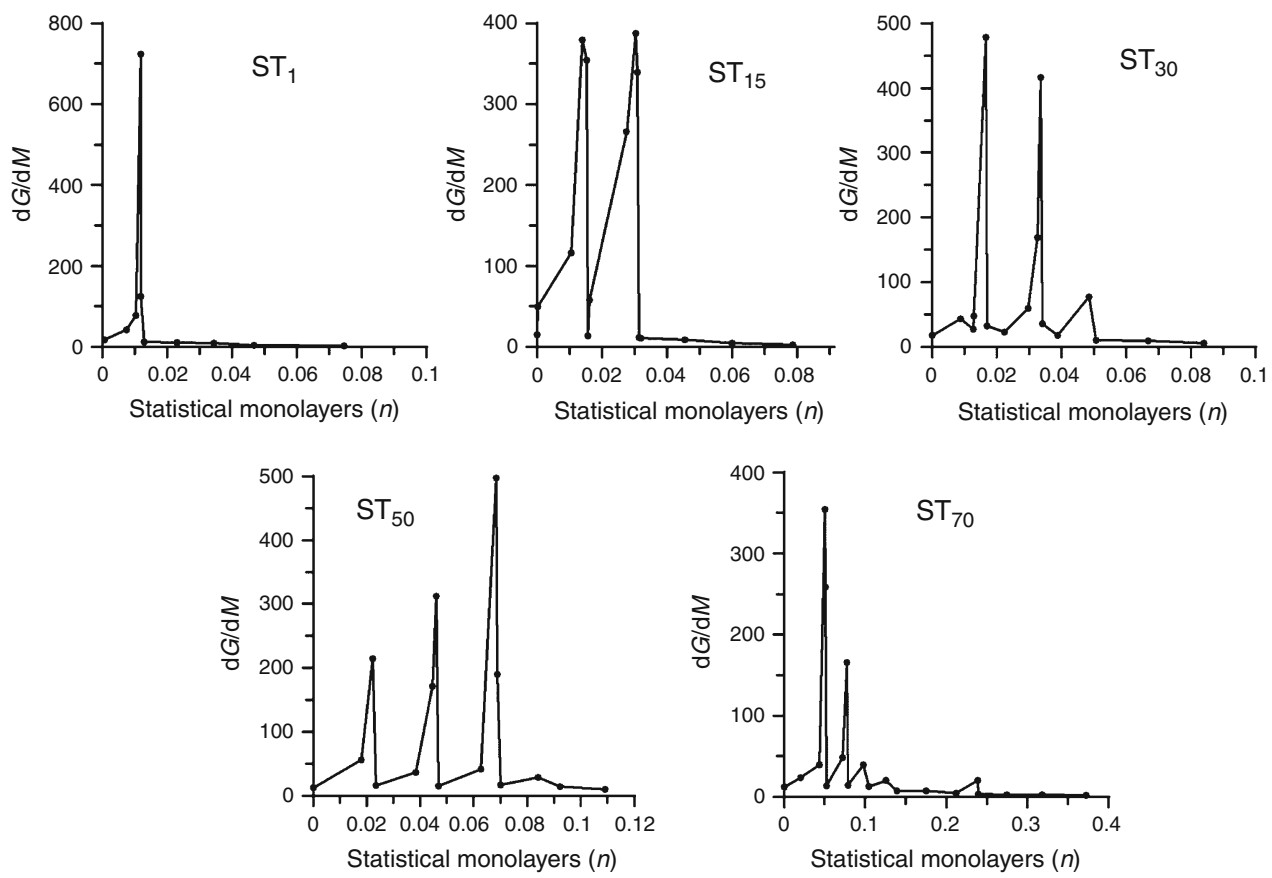
Fig. 7 The dependence of the effective radius of an evaporating drop on the concentration of adsorbed water
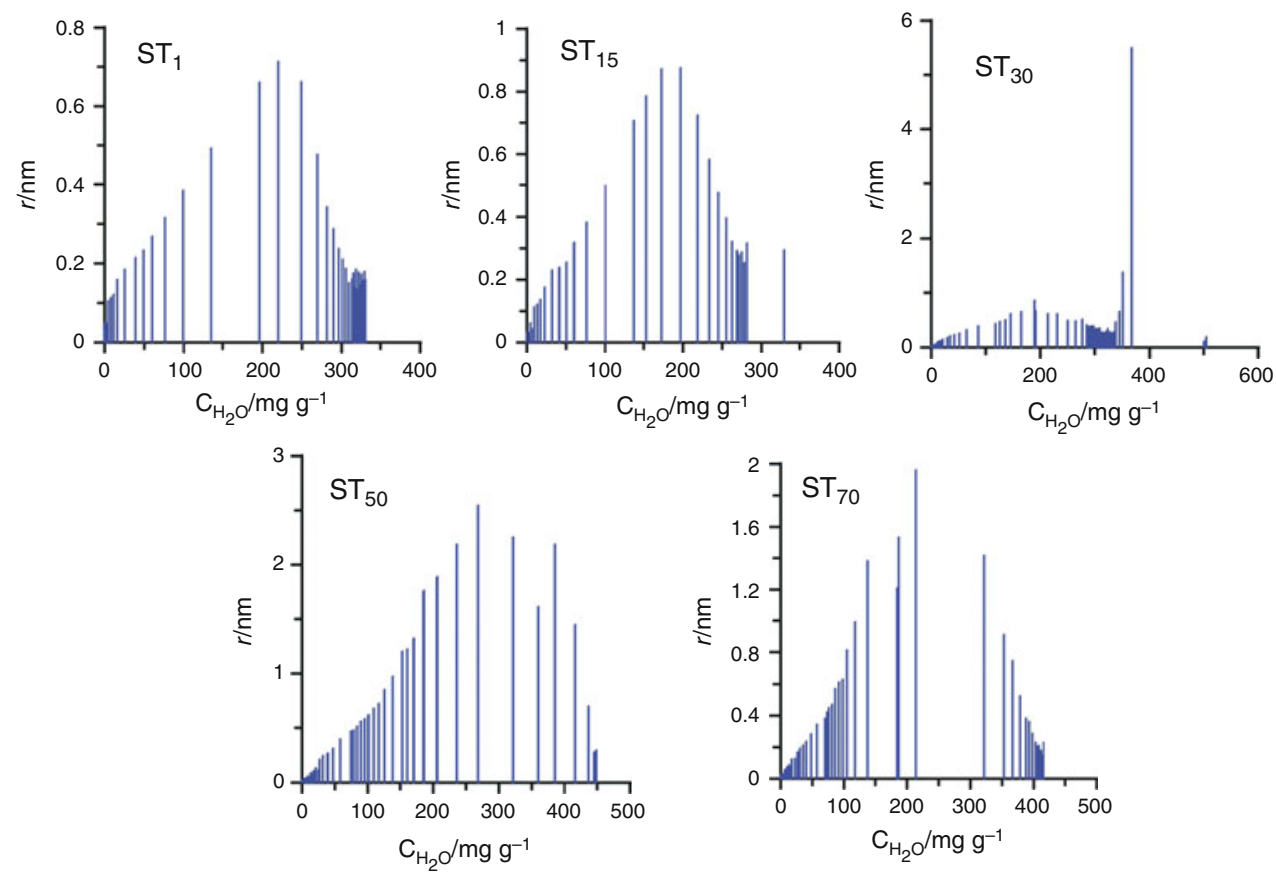

the case of the parameter $\left(\Delta G_{\Sigma}^{\mathrm{s}}\right)$, a similar tendency can be observed except to the adsorbent $\mathrm{ST}_{30}$ which is characterized by the highest value surface free energy at the adsorbent/strongly bound water interface (Fig. 5).

Figure 6 shows the $\mathrm{dG} / \mathrm{dM}$ dependences as the function of statistical water monolayers, under the conditions of low coverage of adsorbent surface with water, where $\mathrm{dG} / \mathrm{dM}$ is change in free energy of system with water mass changes. The value of the $\mathrm{d} G / \mathrm{d} M$ derivative can be used as the analog of chemical potential in the description of isobaric process of thermodesorption. On the presented dependences one or two maxima can be observed, which indicate the formation of various types of water molecule clusters on the heterogeneous surface of the adsorbents under investigation. For the adsorbents of the smallest content of $\mathrm{TiO}_{2}\left(\mathrm{ST}_{1}\right.$ and $\mathrm{ST}_{15}$ samples), there occurs a smaller number of maxima compared to other adsorbents (Fig. 6). Moreover, with the increasing amount of $\mathrm{TiO}_{2}$ the observed maxima occur at thicker and thicker layers of adsorbed water, from 0.01 for $\mathrm{ST}_{1}$ up to 0.25 for the $\mathrm{ST}_{70}$ sample (Fig. 6).

Figure 7 shows the influence of the adsorbed water concentration on the effective radius of evaporated drops of water for the studied adsorbents. Comparing the obtained results with the data in Table 1, one can assume that the average radius of the evaporating drop has the size close to $R_{\text {ave }}$ of the adsorbent. The numerical values of calculated radii should be treated with caution. The reason is that the basic assumption was the spherical shape of the drop and that the surface tension on the partition boundary is equal to that tension at the water/air interface. Actually a large 
part of the drop outline is limited by the adsorbent surface. For this surface there should be chosen a different value of interface tension from that of surface tension.

The curves reflecting the energetic effects connected with water freezing inside the pores of investigated samples are presented in Fig. 8. Water contained in the pores of materials of strong adsorption properties is characterized by quite different physicochemical properties from those of volumetric water. In the case of the adsorbents possessing a well developed structure of micropores $\left(\mathrm{ST}_{1}, \mathrm{ST}_{15}\right.$, and $\mathrm{ST}_{30}$ ), the peaks of water freezing with the maximum at $42{ }^{\circ} \mathrm{C}$ are observed. This is caused by large impact of adsorbents surface (mainly micropores) on water molecules. In the case of the adsorbent with the intermediate content of $\mathrm{TiO}_{2}\left(\mathrm{ST}_{30}\right)$ there is observed the additional, distinctly formed peak of water freezing at $-13{ }^{\circ} \mathrm{C}$ corresponding to that in the wider pores. This confirms the bimodal structure of this adsorbent. The peaks of water freezing for the $\mathrm{ST}_{50}$ and $\mathrm{ST}_{70}$ samples appear at about $22{ }^{\circ} \mathrm{C}$, and their shapes indicate a large content of wide pores confirming the conclusion about their porous structure (Table 1; Fig. 1) and observations that water affected by the interactions with the surface of studied materials changes their physicochemical properties.

\section{Conclusions}

From the results of low-temperature adsorption-desorption of nitrogen measurements it was stated that the surface area of the obtained adsorbents varies from $924.1 \mathrm{~m}^{2} / \mathrm{g}(1 \%$ $\left.\mathrm{TiO}_{2}\right)$ to $353.4 \mathrm{~m}^{2} / \mathrm{g}\left(70 \% \mathrm{TiO}_{2}\right)$. The increase of the $\mathrm{TiO}_{2}$ content in the silica-titania adsorbents results in the decrease of both its specific surface area and contribution of pores to its structure. The process of water thermodesorption from the surface of studied materials proceeds in two or three stages because of the pore distribution and $\mathrm{TiO}_{2}$ content. With the increase of $\mathrm{TiO}_{2}$ content in the studied adsorbents the values of total surface free energy $\left(\Delta G_{\Sigma}\right)$ increase. The largest value of the free surface energy at the adsorbent/strongly bound water interface is exhibited by the adsorbent of intermediate content (30\%) of $\mathrm{TiO}_{2}$. Different types of adsorbed water clusters occur with a larger extent of pores filling along with the increasing content of $\mathrm{TiO}_{2}$ in the sample. Freezing temperature of water contained in the pores of studied materials depends largely on their porous structure. Water freezing in micropores of the tested materials proceed at about $-42{ }^{\circ} \mathrm{C}$, whereas, the water contained in wider pores freezes already at $-22{ }^{\circ} \mathrm{C}$. Due to the well developed porous structure, the water freezing process is a multi-stage one.
Acknowledgements This article was supported by the European Community FP7 under the Marie Curie International Research Staff Exchange Scheme (IRSES). Project No 230790.

Open Access This article is distributed under the terms of the Creative Commons Attribution Noncommercial License which permits any noncommercial use, distribution, and reproduction in any medium, provided the original author(s) and source are credited.

\section{References}

1. Kresge CT, Leonowicz ME, Roth WJ, Vartuli JC, Beck JS. Ordered mesoporous molecular sieves synthesized by a liquidcrystal template mechanism. Nature. 1992;359:710-2.

2. Blasco T, Corma A, Navarro MT, Pariente JP. Synthesis, characterization and catalytic activity of Ti-MCM-41 structures. J Catal. 1995; 156:65-74.

3. Corma A. From microporous to mesoporous molecular sieve materials and their use in catalysis. Chem Rev. 1997;97:2373-419.

4. Orlov A, Zhai QZ, Klinowski J. Photocatalytic properties of the SBA-15 mesoporous silica molecular sieve modified with titanium. J Mater Sci. 2006;41:2187-93.

5. Shen S, Deng Y, Zhu G, Mao D, Wang Y, Wu G, Li J, Liu X, Zhao D. Synthesis and characterization of Ti-SBA-16 ordered mesoporous silica composite. J Mater Sci. 2007;42:7057-61.

6. Tanev PT, Chibwe M, Pinnavaia TJ. Titanium-containing mesoporous molecular sieves for catalytic oxidation of aromatic compounds. Nature. 1994;368:321-3.

7. Koyano KA, Tatsumi T. Synthesis of titanium-containing MCM41. Microporous Mater. 1997;10:259-71.

8. Campostrini R, Ischia M, Palmisano L. Pyrolysis study of sol-gel derived $\mathrm{TiO}_{2}$ powders: part $\mathrm{I}$. $\mathrm{TiO}_{2}$-anatase prepared by reacting titanium(IV) isopropoxide with formic acid. J Therm Anal Calorim. 2003;71:997-1009.

9. Balek V, Todorova N, Trapalis C, Štengl V, Večerníková E, Šubrt J, Malek Z, Kordas G. Thermal behavior of $\mathrm{Fe}_{2} \mathrm{O}_{3} / \mathrm{TiO}_{2}$ mesoporous gels. J Therm Anal Calorim. 2005;80:503-9.

10. Balek V, Subrt J, Bountseva IM, Irie H, Hashimoto K. Emanation thermal analysis study of $\mathrm{N}$-doped titania photoactive powders. J Therm Anal Calorim. 2008;92:161-7.

11. Mousa MA, Farid T, Omran ZA, Allah EMD. Physicochemical studies on the $\mathrm{TiO}_{2}$-silica gel system. J Therm Anal Calorim. 1994;42:1103-12.

12. Corma A, Kan Q, Rey F. Synthesis of Si and Ti-Si-MCM-48 mesoporous materials with controlled pore sizes in the absence of polar organic additives and alkali metal ions. Chem Commun. 1998;579-580.

13. Sayari A, Liu P. Non-silica periodic mesostructured materials: recent progress. Microporous Mater. 1997;12:149-77.

14. Yanishpolskii VV, Pavlenko AN, Tertykh VA, Il'in VG, Leboda R, Skubiszewska-Zięba J. Mesoporous titanium-containing silicas. Synthesis and geometrical characteristics. J Therm Anal Calorim. 2000;62:569-73.

15. Tasbihi M, Stangar UL, Skapin AS, Ristic A, Kaucic V, Tusar NN. Titanium-containing mesoporous silica powders: structural properties and photocatalytic activity towards isopropanol degradation. J Photochem Photobiol A. 2005;169:101-7.

16. Yin H, Wada Y, Kitamura T, Kambe S, Murasawa S, Mori H, Sakata T, Yanagida S. Hydrothermal synthesis of nanosized anatase and rutile $\mathrm{TiO}_{2}$ using amorphous phase $\mathrm{TiO}_{2}$. J Mater Chem. 2001;11:1694-703.

17. Mihai GD, Meynen V, Beyers E, Mertens M, Bilba N, Cool P, Vansant EF. Synthesis, structural characterization and 
photocatalytic activity of Ti-MCM-41 mesoporous molecular sieves. J Porous Mater. 2009;16:109-18.

18. Luan Z, Meloni PA, Czernuszewicz RS, Kevan L. Raman spectroscopy of vanadium oxide species immobilized at surface titanium centers of mesoporous titanosilicate TiMCM-41 molecular sieves. J Phys Chem B. 1997;101:9046-51.

19. Bourlinos AB, Karakassides MA, Petridis D. Synthesis and characterization of iron-containing MCM- 41 porous silica by the exchange method of the template. J Phys Chem B. 2000;104: 4375-80.

20. Hagen A, Schueler K, Roessner F. The performance of the TiMCM-41 in aqueous media and after mechanical treatment studied by in situ xanes, uv/vis and test reactions. Microporous Mesoporous Mat. 2002;51:23-33.

21. Kornatowski J, Wichterlova B, Jitkovsky J, Loffler E, Pilz W. Spectroscopic studies of vanadium-substituted zeolitic silicates of MFI topology. J Chem Soc Faraday Trans. 1996;92:1067-78.

22. Crişan M, Brăileanu A, Crişan D, Răileanu M, Drăgan N, Mardare D, Teodorescu V, Ianculescu A, Bîrjega R, Dumitru M. Thermal behaviour study of some sol-gel $\mathrm{TiO}_{2}$ based materials. J Therm Anal Calorim. 2008;92:7-13.

23. Nishide $T$, Tanaka $T$, Yabe $T$. Temperature programmed desorption analysis of sol-gel-derived titanium films: design of a sol preparation procedure. J Therm Anal Calorim. 2007;90: 373-8.

24. Ingo GM, Riccucci $C$, Bultrini G, Dirè $S$, Chiozzini G. Thermal and microchemical characterisation of sol-gel $\mathrm{SiO}_{2}, \mathrm{TiO}_{2}$ and $x \mathrm{SiO}_{2}-(1-x) \mathrm{TiO}_{2}$ ceramic materials. $\mathrm{J}$ Therm Anal Calorim. 2001;66:37-46.

25. Cides da Silva LC, Araujo GLB, Segismundo NR, Moscardini EF, Mercuri LP, Cosentino IC, Fantini MCA, Matos JR. DSC estimation of structural and textural parameters of SBA-15 silica using water probe. J Therm Anal Calorim. 2009;97:701-4.

26. Marinescu C, Sofronia A, Rusti C, Piticescu R, Badilita V, Vasile $\mathrm{E}$, Baies R, Tanasescu S. DSC investigation of nanocrystalline TiO2 powder. J Therm Anal Calorim. 2011;103:49-57.

27. Wan Q, Ramsey Ch, Baran G. Thermal pretreatment of silica composite filler materials. J Therm Anal Calorim. 2010;99: 237-43.

28. Gregg SJ, Sing KSW. Adsorption, surface area and porosity. London: Academic Press; 1982.

29. Barrett EP, Joyner LG, Halenda PP. The determination of pore volumes and area distributions in porous substances. J Am Chem Soc. 1951;73:373-80.

30. Turov VV, Leboda R, Skubiszewska-Zięba J, Charmas B. Application of quasi-isothermal thermogravimetry for estimation of some properties of hydration layers in mesoporous adsorbents. Colloid Surf A. 2001;181:1-9.

31. Skubiszewska-Zięba J. Structural and energetic properties of carbosils hydrothermally treated in the autoclave or the microwave reactor. Adsorption. 2008;14:695-709. 